\title{
Diagnostic Invasiveness and Psychosocial Consequences of False-Positive Mammography
}

Bruno Heleno, MD

Volkert Dirk Siersma, $\mathrm{PbD}$

Jobn Brodersen, $\mathrm{PbD}$

The Research Unit for General Practice and Section of General Practice, Department of Public Health, University of Copenhagen, Copenhagen, Denmark

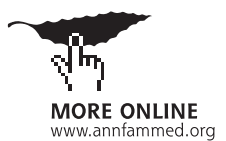

Conflicts of interest: authors report none.

\section{CORRESPONDING AUTHOR}

Bruno Heleno, MD

The Research Unit for General Practice and Section of General Practice Department of Public Health University of Copenhagen

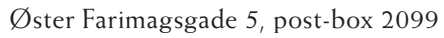
1014 Copenhagen K, Denmark bruno.heleno@sund.ku.dk

\begin{abstract}
PURPOSE We undertook a study to assess whether women with false-positive mammography have worse psychosocial consequences if managed with a workup that involves a biopsy (invasive group) than if managed with only additional imaging (noninvasive group).
\end{abstract}

METHODS We performed subgroup analysis of a cohort study of 454 women with abnormal screening mammography and 908 matched control women with normal results. Using a condition-specific questionnaire (Consequences of Screening in Breast (ancer), we assessed 12 psychosocial consequences at 5 time points $(0,1,6,18$, and 36 months after final diagnosis) and compared the 2 groups of women with false-positives (invasive and noninvasive management groups).

RESULTS Among the 252 women with false-positive mammography eligible for this study, psychosocial consequences were similar for those managed invasively and those managed noninvasively during the 36 months of follow-up. In 60 comparisons ( 12 scales and 5 time points), differences between the groups were never statistically significant $(P<.01)$ and the point estimates for the differences were always close to zero. The psychosocial consequences of women with falsepositive results, regardless of management, fell between those of women with normal mammography and those of women determined to have breast cancer.

CONCLUSIONS We found no evidence that use of more invasive diagnostics was associated with worse psychosocial consequences. It is therefore reasonable to pool subgroups of women with false-positives in a single analysis. The invasiveness of subsequent diagnostic procedures does not help to identify women at higher risk for adverse psychosocial consequences of false-positive mammography.

Ann Fam Med 2015;13:242-249. doi: 10.1370/afm.1762.

\section{INTRODUCTION}

he psychological consequences of false-positive findings are among the important harms of mammography screening..$^{1-3}$ Several observational studies have assessed these consequences and their results have been summarized in systematic reviews. On average, women with false-positive mammography experience more negative psychosocial consequences than women with normal mammography. ${ }^{4-9}$

It is possible that increasingly invasive diagnostic procedures after positive mammography lead to worse psychosocial consequences. ${ }^{9}$ Women having such management will wait longer for final results, may endure repeated consultations and investigations, and may think the invasiveness of the test is related with the likelihood of cancer. ${ }^{10-12}$ There is little direct evidence, however, supporting this claim. Of the studies that have looked into psychosocial consequences of mammography screening, few stratified the analysis by type of diagnostic testing, and their results seem conflicting. Worse psychosocial consequences in women undergoing increasingly invasive tests have been found in some studies ${ }^{11,13-15}$ but not in others. ${ }^{16,17}$ The disparity is not inconsistent as the studies were not powered to detect differences between subgroups of women with false- 
positives. Nevertheless, as a result, the field still lacks a definitive answer as to whether psychosocial harm increases with progressively more invasive tests.

There are 2 important reasons to assess whether psychosocial harm increases when subsequent diagnostic tests are invasive. The first reason is methodologic: most studies have considered women with false-positives to be homogenous enough that they can be pooled together in a single category, and it is useful to test whether this is a reasonable assumption..$^{18}$ The second reason has wider clinical relevance. Women with false-positives vary widely in their psychosocial response, and it would be useful to find predictors of higher distress that could be used to target interventions. Diagnostic test invasiveness is attractive because it can be unambiguously detected and it is actionable.

We have shown in a cohort of women screened with mammography and followed-up for 36 months that false-positives were associated with negative longterm psychosocial consequences. ${ }^{19}$ In the same cohort, we now wanted to assess whether women with falsepositive mammography managed with a workup that involved a biopsy (invasive group) had worse psychosocial consequences than women managed only with additional imaging (noninvasive group).

\section{METHODS}

We used a fixed cohort design with repeated measurements. The protocol and a list of protocol deviations are available as Supplemental Material, available at http://www.annfammed.org/content/13/3/242/suppl/ DC1. The study was approved by the Danish Data Protection Agency, 2007-41-0777; approval from the ethics committee was not required.

\section{Participants}

This study was nested in a larger cohort study, and details on participants and data collection methods have been previously described ${ }^{19}$ Briefly, from June 3, 2004 , to June 2, 2005, women aged 50 to 69 years with abnormal mammography findings were consecutively enrolled from 2 screening programs (Copenhagen and Funen, Denmark). For each woman with abnormal findings, 2 additional women with normal findings were selected (matched for screening clinic and day of screening appointment). For this study, we selected the subcohort of women with false-positive mammography.

\section{Exposures}

Women with false-positive mammography were divided in 2 main exposure groups according to the extent of workup. The first consisted of women who underwent clinical examination, breast ultrasound, and
3 -projection mammography (the noninvasive management group). The second had these 3 procedures plus either fine-needle, core needle, or surgical biopsy (the invasive management group). We excluded women who were invited to repeat mammography in 3 to 6 months (early recall) from the main analysis. An earlier study showed that women invited for early recall had worse psychosocial consequences than those who had immediate additional imaging ${ }^{11}$; thus, including women with early recall in the noninvasive management group would decrease the contrast between women managed noninvasively and women managed invasively.

Our study had 36 months of follow-up and, in Denmark, women are invited to screening every 24 months. In this study, however, we assumed that exposures did not change with time, that is, if a woman who was in the noninvasive group at inception required an invasive test 24 months later because of a suspicious finding in her next screening round, she was still analyzed in the noninvasive group.

\section{Outcomes}

We assessed psychosocial consequences with a condition-specific questionnaire-the Consequences of Screening in Breast Cancer (COS-BC) — whose content validity, psychometric properties, and invariance in relation to time have been previously demonstrated. ${ }^{20-22}$ This questionnaire consists of 2 parts: part 1 measures the psychosocial consequences of abnormal screening mammography, and part 2 measures the long-term psychosocial consequences of false-positives. Higher scores on part 1 reflect greater negative psychosocial consequences. Higher scores on part 2 reflect changes in psychosocial dimensions, regardless of whether this change was positive or negative.

Women with abnormal mammography results completed a baseline COS-BC when they attended the recall clinic before they had their additional examinations, while women with normal findings were mailed part 1 of the COS-BC 1 week after receiving the letter with their results. Subsequently, women from both groups were mailed the COS-BC (parts 1 and 2) at the same time points: 1, 6, 18, and 36 months after their final diagnosis. Women were asked to return the questionnaires using a prestamped return envelope. A reminder was sent within 2 weeks if no response was obtained.

We assessed 12 prespecified psychosocial consequences, 1 for each component of the COS-BC. In part 1, we measured the following constructs: Sense of Dejection, Anxiety, Negative Impact on Behavior, Sleep Disturbance, Degree of Breast Self-Examination, Negative Impact on Sexuality, and the 2 single items, Feeling Less Attractive and Busy to Take My Mind Off Things. In part 2, we measured the following 
constructs: Worries About Breast Cancer, Inner Calm, Social Network, and Existential Values.

To assess the rigor of our main results, we performed 2 sensitivity analyses. In the first, we repeated analyses after including in the noninvasive management group women who had early recall. In the second, we used a composite outcome supported by a confirmatory factor analysis ${ }^{21}$ : a sum-score of the raw scores of all 29 items on part 1 of the COS-BC, which can be more sensitive to differences in psychosocial consequences than the individual scales because of its larger number of items.

\section{Confounders}

We used the first questionnaire to collect data on 4 potential confounders: age, social class, employment, and whether the woman lived alone. Age was treated as a continuous variable.

\section{Statistical Analyses}

We performed a post hoc subgroup analysis of a cohort study to assess the psychosocial consequences of false-positive screening mammography. Our sample size was determined by the number of women attending screening in the study centers over a 1 -year period.

Baseline data across the 2 categories of exposure (invasive management vs noninvasive management) were compared with the $\chi^{2}$ test for categorical data and with the Wilcoxon signed rank test for continuous variables.

We analyzed the mean score for each outcome over time using linear regression models. We used both crude models and models adjusted for the 4 potential confounders assessed. Generalized estimating equation methods were used to account for repeated measurement on the same woman. During follow-up, participation was likely influenced by the exposure category and by the psychosocial consequences; therefore, we used inverse probability weighting methods to address the potential differential dropout. ${ }^{23}$

With 12 outcomes and 5 time points, we were able to perform up to 60 comparisons. Multiple testing was addressed in the following way. For the analyses of the invasiveness of management-our main interest—we assessed all 12 prespecified psychosocial consequences and defined significance at the $P<.01$ level. To explore whether lack of difference between groups could be due to overly conservative significance, we also performed an analysis using only the composite sum-score and a $P<.05$ significance.

Whenever an item on a scale was not completed, we set the scale to missing. In addition, for the scale about sexuality, women could reply that the items were "not applicable." In this case, we again set the scale to missing. Missing single-items or scales set to missing were not included in the analyses.

All analyses were performed with SAS 9.3 (SAS Institute, Inc).

\section{RESULTS}

Selection of study participants is shown in Figure 1. Of our original cohort of 1,362 screened women (454 women with abnormal screening mammography and 908 matched control women with normal results), 272 had false-positive mammography results and 252 were eligible for this study. Baseline characteristics of women with noninvasive and invasive management are displayed in Table 1.

We found no statistically significant differences between groups in any psychosocial consequences at any time point, either in unadjusted analyses (Figures 2 and 3 ) or in adjusted analyses (Table 2). In most

\begin{tabular}{|c|c|c|c|c|}
\hline \multirow[b]{2}{*}{ Characteristic } & \multirow[b]{2}{*}{$\begin{array}{c}\text { Total } \\
(\mathrm{N}=252)\end{array}$} & \multicolumn{2}{|c|}{ Management Group } & \multirow[b]{2}{*}{$\begin{array}{c}P \\
\text { Value }\end{array}$} \\
\hline & & $\begin{array}{c}\text { Noninvasive } \\
(n=170)\end{array}$ & $\begin{array}{l}\text { Invasive } \\
(n=82)\end{array}$ & \\
\hline \multicolumn{5}{|l|}{ Age-group, No. (\%) } \\
\hline $50-54 y$ & $106(42.1)$ & $75(44.1)$ & $31(37.8)$ & .74 \\
\hline $55-59 y$ & $62(24.6)$ & $42(24.7)$ & $20(24.4)$ & \\
\hline $60-64$ y & $43(17.1)$ & $27(15.9)$ & $16(19.5)$ & \\
\hline$\geq 65 \mathrm{y}$ & $41(16.3)$ & $26(15.3)$ & $15(18.3)$ & \\
\hline Age, median (IQR), y & $\begin{array}{l}56.8 \\
(53.2-62.3)\end{array}$ & $\begin{array}{l}56.8 \\
(52.8-61.7)\end{array}$ & $\begin{array}{l}57.0 \\
(53.2-62.6)\end{array}$ & .41 \\
\hline \multicolumn{5}{|l|}{ Living alone, No. (\%) } \\
\hline No & $173(70.9)$ & $121(72.9)$ & $52(66.7)$ & .32 \\
\hline Yes & $71(29.1)$ & $45(27.1)$ & $26(33.3)$ & \\
\hline \multicolumn{5}{|c|}{ Employment status, No. (\%) } \\
\hline Working & $138(56.6)$ & $92(55.4)$ & $46(59.0)$ & .83 \\
\hline Unemployed & $8(3.3)$ & $6(11.8)$ & $2(2.6)$ & \\
\hline Pensioned & $98(40.2)$ & $68(41.0)$ & $30(38.5)$ & \\
\hline \multicolumn{5}{|l|}{ Social class, ${ }^{a}$ No. (\%) } \\
\hline I (highest) & $5(2.1)$ & $3(1.8)$ & $2(2.6)$ & .64 \\
\hline$\|$ & $36(14.8)$ & $26(15.8)$ & $10(12.8)$ & \\
\hline III & $49(20.2)$ & $29(17.6)$ & $20(25.6)$ & \\
\hline IV & $87(35.8)$ & $60(36.4)$ & $27(34.6)$ & \\
\hline v & $66(27.2)$ & $47(28.5)$ & $19(24.4)$ & \\
\hline
\end{tabular}




\section{Figure 1. Diagram of participation showing the number of women with false-positives and type of management.}

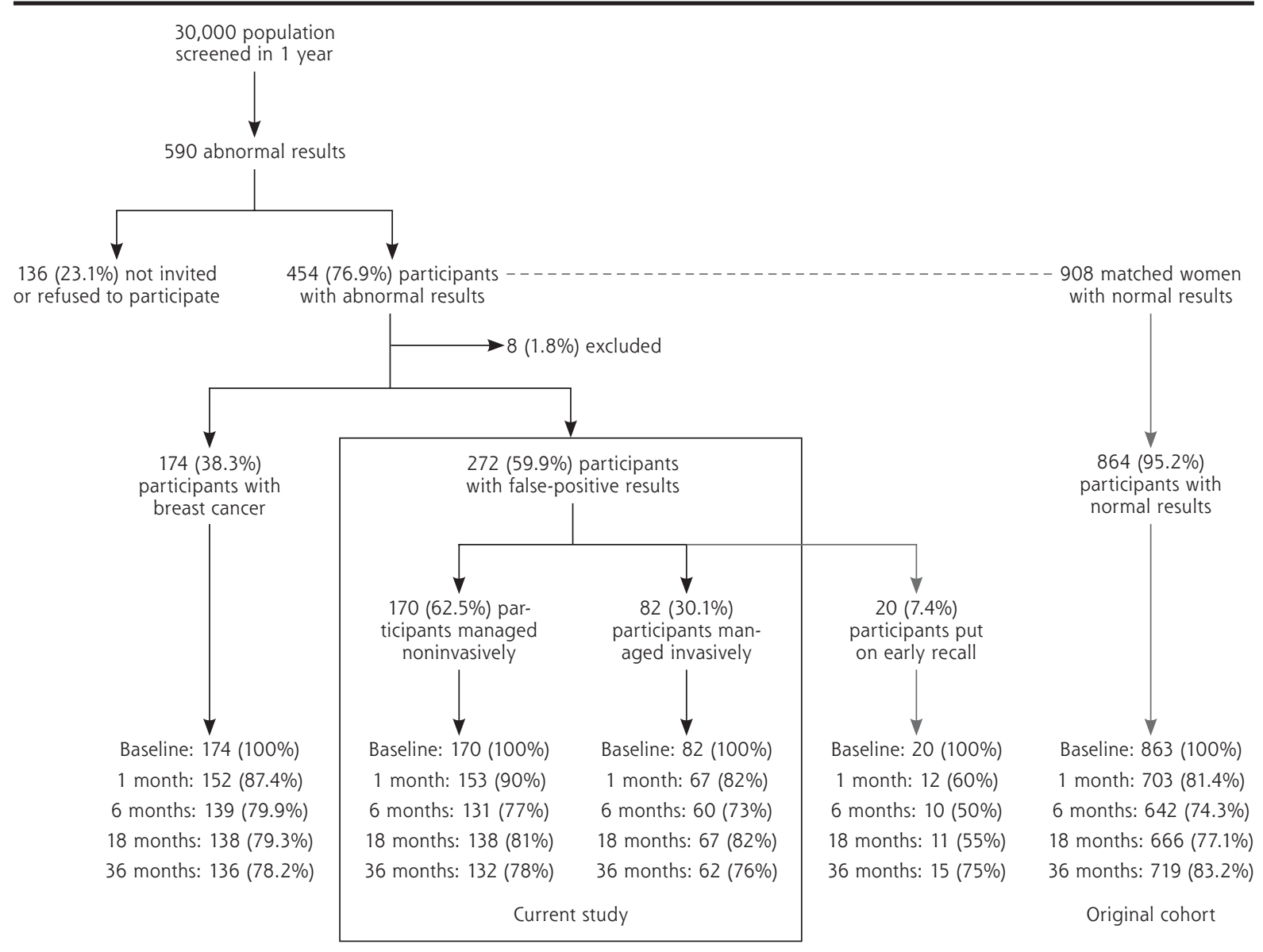

Notes: The response rates to the survey at baseline and 1, 6,18 , and 36 months are shown in the boxes. For completeness, the numbers and distribution of women in the original cohort are also provided.

scales of part 1 of the COS-BC (Figure 2 and Table 2 ), women managed with invasive procedures seem to experience more negative psychosocial consequences than those managed noninvasively up to 6 months. At subsequent time points, however, the pattern appeared reversed: at 36 months, women managed invasively seem to experience less psychosocial harm than those managed with immediate mammography. We found no consistent pattern in the scales measuring longterm consequences of breast screening (Figure 3 and Table 2).

Our main results held up in 2 sensitivity analyses. In the first, where we included data of women in the noninvasive group who were put on early recall, results again showed no statistically significant differences between women managed invasively and noninvasively (Supplemental Table 1, http://www.annfammed.org/ content/13/3/242/suppl/DC1). In the second, where we used a more sensitive post hoc sum-score, we likewise did not find any significant differences between groups (Supplemental Figure 1, http://www.annfammed.org/ content/13/3/242/suppl/DC1).

Finally, psychosocial consequences for women with normal results and women with breast cancer are also presented in Figures 2 and 3 (the corresponding adjusted figures in Supplemental Tables 3 and 4, http://www.annfammed.org/content/13/3/242/suppl/ DC1). These data, previously reported ${ }_{1}^{19}$ are shown here only to help to interpret our current results. Women with normal mammography findings are expected to be the least affected by mammography and provide a lower bound for the COS-BC results at each time point. Women with breast cancer are expected to be the most affected and provide an upper bound for the COS-BC results. The psychosocial consequences of women with false-positive results managed noninvasively and invasively are between these 2 groups in every time point. 
Figure 2. Psychosocial consequences of abnormal screening mammography over time, measured by part 1 of the Consequences of Screening-Breast Cancer (COS-BC) questionnaire.

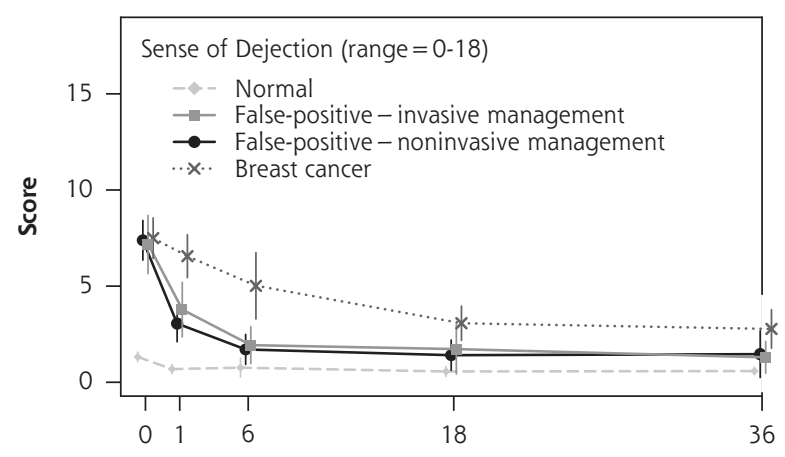

Months after screening
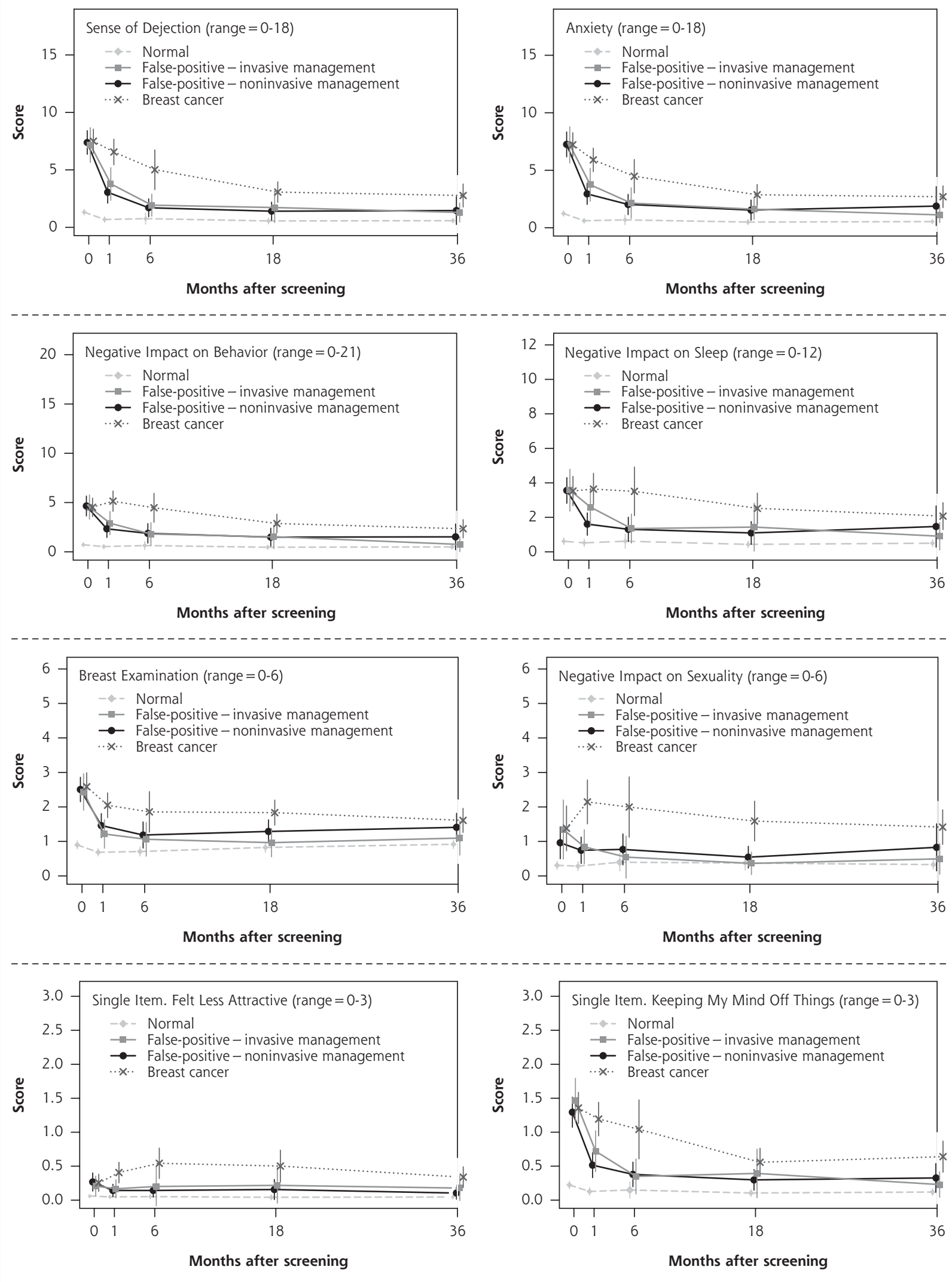

Notes: The figure shows the mean score of each of the 6 scales and 2 single items of part 1 of COS-BC (y axis), for the 2 groups of women with false-positive mammography at 5 time points: $0,1,6,18$, and 36 months (y axis). The mean scores for women with breast cancer and women with normal mammography are also shown for completeness. Higher scores indicate greater negative psychosocial outcome. 
Figure 3. Long-term psychosocial consequences of false-positive mammography over time, measured by part 2 of the Consequences of Screening-Breast Cancer (COS-BC) questionnaire.
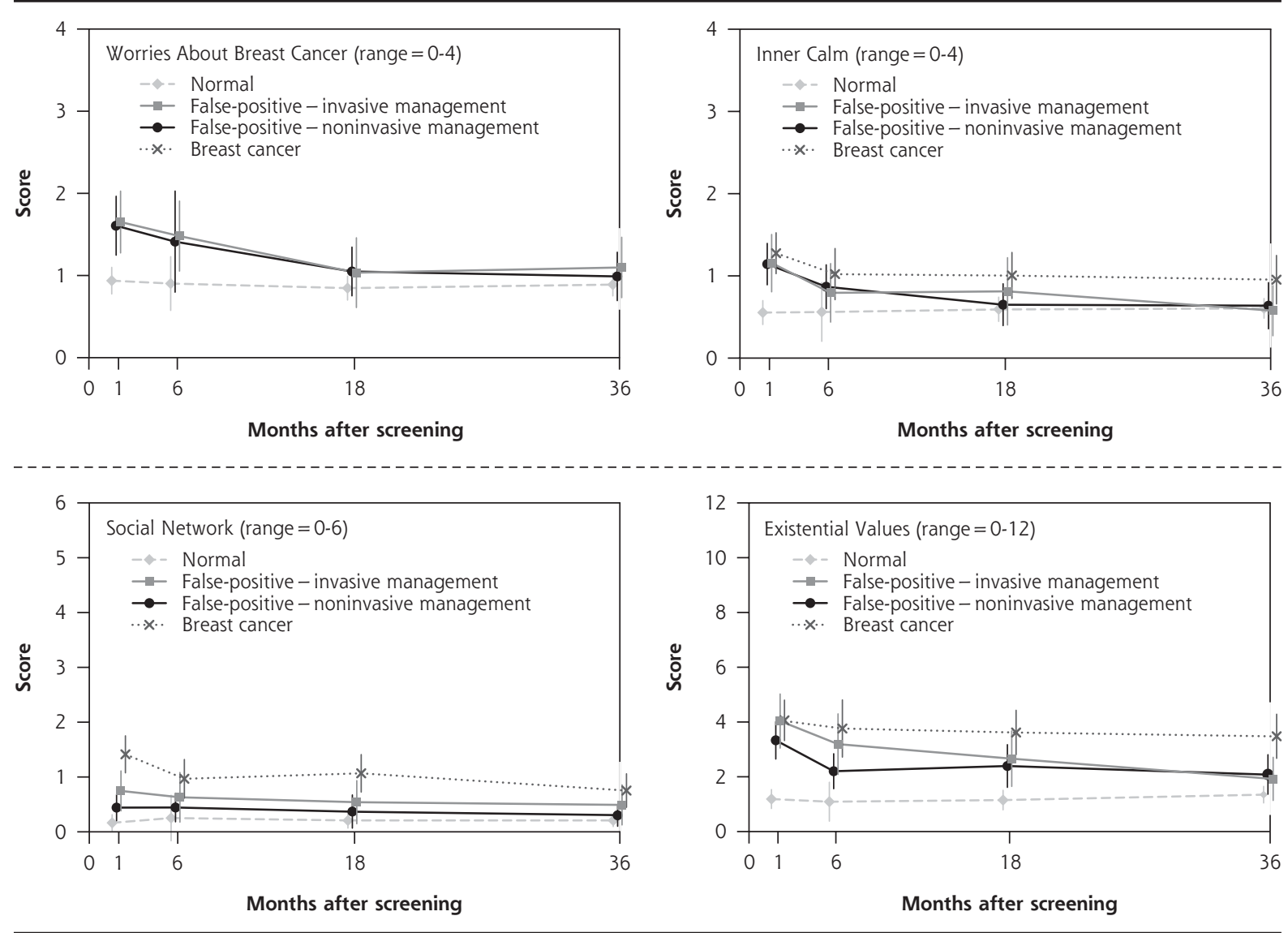

Notes: The figure shows the mean score of each of the 4 scales of part 2 of COS-BC ( $y$ axis), for the 2 groups of women with false-positive mammography. The questions about long-term consequences were relevant only after women were informed of their diagnosis; therefore, they were assessed at 4 time points: 1,6 , 18 , and 36 months (y axis). The mean scores for women with breast cancer and women with normal mammography are also shown for completeness. Higher scores reflect changes in psychosocial dimensions, regardless of whether this change was positive or negative.

\section{DISCUSSION}

We did not find any evidence to support our hypothesis that increasing invasiveness of diagnostic procedures after positive mammography is associated with worse negative psychosocial consequences. Regardless of the nature of subsequent diagnostic tests, women with false-positive mammography had psychosocial consequences that were poorer than those of women with normal results and better than those of women with breast cancer.

Our results do not support the hypothesis of worse psychosocial consequences in women managed with invasive procedures. The best estimate for the difference in psychosocial consequences between women managed invasively and noninvasively is close to zero. The CIs are wide, however: they are compatible with differences as large as one-third of the difference between women with cancer and women with normal results. ${ }^{19}$ Our study is therefore still compatible with the previous studies that found an association of invasiveness and psychosocial harm. ${ }^{11,13-15}$ What is puzzling is that although we had 60 comparisons (12 scales and 5 time points), the mean score differences were always close to zero. If women managed invasively fared much worse than women managed noninvasively, we would expect to see the mean score differences to be centered on a large positive value.

In hindsight, our hypothesis had strong resonance with clinicians but weak empirical support. The few similar previous studies available provide mixed results: 4 of them suggested an association of invasiveness and psychosocial harm, ${ }^{13-15}$ whereas 2 found no difference. ${ }^{16,17}$ We can speculate that a small number of women needing invasive procedures could explain why 2 of the studies found no difference. All studies, however, have some methodologic shortcomings: none adjusted their analysis for confounders, it is unclear whether subgroups of women with false-positives were comparable at base- 
Table 2. Psychosocial Consequences of Women With False-Positive Mammography Managed Invasively vs Noninvasively

\begin{tabular}{|c|c|c|c|c|c|}
\hline \multirow{2}{*}{$\begin{array}{l}\text { Scale } \\
\text { (Possible Range) }\end{array}$} & \multicolumn{5}{|c|}{ Mean Difference Between Groups $(\mathrm{Cl})^{a}$} \\
\hline & Baseline & 1 Month & 6 Months & 18 Months & 36 Months \\
\hline Dejection $(0-18)^{b}$ & $\begin{array}{c}-0.14 \\
(-1.95 \text { to } 1.67)\end{array}$ & $0.79(-0.86$ to 2.44$)$ & $0.17(-0.94$ to 1.29$)$ & $0.68(-0.80$ to 2.16$)$ & $-0.27(-1.60$ to 1.07$)$ \\
\hline Anxiety $(0-18)^{b}$ & $\begin{array}{c}-0.27 \\
(-2.09 \text { to } 1.55)\end{array}$ & $0.84(-0.76$ to 2.44$)$ & $0.41(-1.03$ to 1.84$)$ & $0.44(-0.77$ to 1.65$)$ & $-0.71(-2.38$ to 0.96$)$ \\
\hline $\begin{array}{l}\text { Negative Impact on } \\
\text { Behavior }(0-21)^{\mathrm{b}}\end{array}$ & $\begin{array}{c}-0.20 \\
(-1.75 \text { to } 1.35)\end{array}$ & $0.67(-0.74$ to 2.09$)$ & $0.37(-1.06$ to 1.79$)$ & $0.39(-0.99$ to 1.78$)$ & $-0.72(-2.17$ to 0.72$)$ \\
\hline $\begin{array}{l}\text { Negative Impact on } \\
\text { Sleep }(0-12)^{b}\end{array}$ & $\begin{array}{c}-0.21 \\
(-1.56 \text { to } 1.14)\end{array}$ & $0.75(-0.41$ to 1.90$)$ & $0.10(-0.68$ to 0.88$)$ & $0.54(-0.97$ to 2.05$)$ & $-0.62(-1.94$ to 0.71$)$ \\
\hline $\begin{array}{l}\text { Breast Examination } \\
(0-6)^{b}\end{array}$ & $\begin{array}{c}0.09 \\
(-0.54 \text { to } 0.73)\end{array}$ & $-0.06(-0.60$ to 0.48$)$ & $0.06(-0.59$ to 0.71$)$ & $-0.06(-0.59$ to 0.47$)$ & $-0.07(-0.70$ to 0.56$)$ \\
\hline $\begin{array}{l}\text { Negative Impact on } \\
\text { Sexuality }(0-6)^{\mathrm{b}}\end{array}$ & $\begin{array}{c}0.49 \\
(-0.49 \text { to } 1.47)\end{array}$ & $0.15(-0.44$ to 0.73$)$ & $-0.14(-0.88$ to 0.61$)$ & $0.02(-0.37$ to 0.42$)$ & $-0.30(-1.07$ to 0.47$)$ \\
\hline $\begin{array}{l}\text { Felt Less Attractive } \\
(0-3)^{\mathrm{b}}\end{array}$ & $\begin{array}{c}-0.08 \\
(-0.25 \text { to } 0.10)\end{array}$ & $0.02(-0.13$ to 0.17$)$ & $0.07(-0.22$ to 0.37$)$ & $0.12(-0.21$ to 0.45$)$ & $0.05(-0.14$ to 0.24$)$ \\
\hline $\begin{array}{l}\text { Keeping Mind Off } \\
\text { Things }(0-3)^{\mathrm{b}}\end{array}$ & $\begin{array}{c}0.16 \\
(-0.24 \text { to } 0.55)\end{array}$ & $0.15(-0.19$ to 0.48$)$ & $-0.04(-0.32$ to 0.24$)$ & $0.15(-0.24$ to 0.55$)$ & $-0.10(-0.37$ to 0.17$)$ \\
\hline $\begin{array}{l}\text { Worries About Breast } \\
\text { Cancer }(0-4)^{\mathrm{b}}\end{array}$ & - & $0.29(-0.17$ to 0.74$)$ & $0.30(-0.35$ to 0.95$)$ & $0.06(-0.43$ to 0.56$)$ & $0.17(-0.30$ to 0.64$)$ \\
\hline Inner Calm $(0-4)^{b}$ & - & $0.05(-0.38$ to 0.48$)$ & $0.04(-0.41$ to 0.49$)$ & $0.23(-0.26$ to 0.72$)$ & $-0.07(-0.49$ to 0.35$)$ \\
\hline Social Network $(0-6)^{b}$ & - & $0.31(-0.14$ to 0.76$)$ & $0.25(-0.30$ to 0.80$)$ & $0.20(-0.28$ to 0.69$)$ & $0.22(-0.23$ to 0.67$)$ \\
\hline $\begin{array}{l}\text { Existential Values } \\
(0-12)^{\mathrm{b}}\end{array}$ & - & $0.65(-0.56$ to 1.86$)$ & $1.00(-0.34$ to 2.34$)$ & $0.33(-0.98$ to 1.64$)$ & $-0.55(-1.57$ to 0.48$)$ \\
\hline $\begin{array}{l}\text { Total sum-score of } \\
\text { COS-BC part } 1 \text { (0-87) }\end{array}$ & $\begin{array}{c}2.13 \\
(-5.13 \text { to } 9.39) \\
\end{array}$ & $1.95(-2.97$ to 6.88$)$ & $0.08(-3.12$ to 3.29$)$ & $0.35(-2.78$ to 3.48$)$ & $2.72(-9.69$ to 4.25$)$ \\
\hline \multicolumn{6}{|c|}{ COS-BC $=$ Consequences of Screening in Breast Cancer. } \\
\hline \multicolumn{6}{|c|}{ Notes: Women put on early recall were excluded from the analysis. All analyses were adjusted for age, social class, employment status, and whether the woman lived alone. } \\
\hline $\begin{array}{l}\text { a Positive differences indicat } \\
\text { in the noninvasive group we } \\
\text { b Significance was defined at } \\
\text { ' Significance was defined at }\end{array}$ & $\begin{array}{l}\text { hat women in the inv } \\
\text { more distressed than } \\
<.01 \text { and } 99 \% \mathrm{Cls} \text { a } \\
<.05 \text { and } 95 \% \mathrm{Cls} \text { a }\end{array}$ & $\begin{array}{l}\text { asive group were more distre } \\
\text { women in the invasive grout } \\
\text { e presented. } \\
\text { e presented. }\end{array}$ & ssed than women in the noni & vasive group; negative diffe & ences indicate that women \\
\hline
\end{tabular}

line, and most of them did not address the fact that attrition during follow-up is likely to be related to the degree of psychosocial distress. In summary, most studies have suggested an association between invasiveness and psychosocial consequences, but there are important methodologic limitations in all cases.

Our contribution to this discussion lies in the higher quality of our data and its analysis. This study was conducted in a larger cohort, and it sustained a high response rate during the 36 months of follow-up. In addition, it used a condition-specific questionnaire, which is more responsive to subtle reactions to screening than generic questionnaires. ${ }^{24,25} \mathrm{We}$ applied inverse probability methods to address the higher dropout rate of women with worse psychosocial consequences, possibly generating differential attrition in the 2 groups. Finally, our study was the first to adjust for important confounders in the analysis (age, social class, employment status, and whether women lived alone).

Yet, there are 3 major methodologic concerns: selection bias, residual confounding, and type II error. First, we did not collect data of women who declined to participate, and we cannot tell whether they are systematically different from those included in the study. As women declined to participate in the study before knowing what kind of diagnostic tests would be required, we think it is unlikely that participation was associated with the type of tests performed after the recall visit. Second, we did not adjusted for family history of breast cancer, previous abnormal mammograms, or screenings being the first ever attended. Both groups of women, however, had identical psychosocial consequences on the baseline questionnaire. If there were a strong residual confounding, we would see spurious differences between the 2 groups, even though all women knew at that point was that their screening test was abnormal. Third, type II error (ie, that a true difference was missed) is a problem. To address this issue, we performed 2 sensitivity analyses. In the first, we increased the sample size by including women put on early recalli in the second, we tried to increase the power in our analysis by using a more sensitive outcome (the sum-score) and the traditional .05 significance level. Both analyses yielded results similar to those of our main analysis: our best estimate is no effect of invasiveness, although it is imprecise. In summary, we think that 
neither selection bias nor residual confounding explains why we found no differences according to the invasiveness of workup. It is possible that by adjusting for confounders and differential attrition, we have eliminated some of the differences found in previous studies.

\section{CONCLUSIONS}

Recently, a systematic review suggested that the degree of distress after a false-positive mammography is related to the invasiveness of the subsequent workup. ${ }^{9}$ Our study suggests that there is considerable uncertainty surrounding this claim and that differences reported in the studies included in the review could be explained by confounding and differential attrition. On the basis of our results, the invasiveness of diagnostic interventions does not seem to help identify women at higher risk for severe psychosocial distress after false-positive mammography. In other words, women who require only clinical examination and additional imaging experience the same degree of distress as women who undergo invasive procedures. As such, interventions to limit the psychosocial harm of mammography screening should focus on reducing the total number of false-positive tests.

\section{To read or post commentaries in response to this article, see it online at http://www.annfammed.org/content/13/3/242.}

Key words: mass screening; breast cancer; false-positive reactions/ adverse effects; biopsy; fine-needle/adverse effects; biopsy/adverse effects; mammography/adverse effects

Submitted July 29, 2014; submitted, revised, November 14, 2014; accepted December 11, 2014.

Funding support: B.H. is supported by Fundação para a Ciência e Tecnologia (governmental agency) grant SFRH/BD/74640/2010. V.D.S. and J.B. were supported by internal institutional funding.

Disclaimer: The funders had no role in study design or data collection, analysis, or interpretation.

Acknowledgments: The authors thank Gilbert Welch, Michael Nixon, and Christine Baunsgaard for helpful comments on an earlier draft.

Supplementary materials: Available at http://www.AnnFamMed. org/content/13/3/242/suppl/DC1/

\section{References}

1. Marmot MG, Altman DG, Cameron DA, Dewar JA, Thompson SG, Wilcox M. The benefits and harms of breast cancer screening: an independent review. Br J Cancer. 2013;108(11):2205-2240.

2. Gøtzsche PC, Jørgensen KJ. Screening for breast cancer with mammography. Cochrane Database of Systematic Reviews. http:// onlinelibrary.wiley.com/doi/10.1002/14651858.CD001877.pub5/ abstract. Published Jun 4, 2013. Accessed Jun 14, 2013.

3. Heleno B, Thomsen MF, Rodrigues DS, Jorgensen KJ, Brodersen J. Quantification of harms in cancer screening trials: literature review. BMJ. 2013;347:f5334.
4. Brett J, Bankhead C, Henderson B, Watson E, Austoker J. The psychological impact of mammographic screening. A systematic review. Psychooncology. 2005;14(11):917-938.

5. Brewer NT, Salz T, Lillie SE. Systematic review: the long-term effects of false-positive mammograms. Ann Intern Med. 2007;146(7):502-510.

6. Hafslund B, Nortvedt MW. Mammography screening from the perspective of quality of life: a review of the literature. Scand J Caring Sci. 2009;23(3):539-548.

7. Salz T, Richman AR, Brewer NT. Meta-analyses of the effect of false-positive mammograms on generic and specific psychosocial outcomes. Psychooncology. 2010;19(10):1026-1034.

8. Metsälä E, Pajukari A, Aro AR. Breast cancer worry in further examination of mammography screening - a systematic review. Scand J Caring Sci. 2012;26(4):773-786.

9. Bond M, Pavey T, Welch K, et al. Systematic review of the psychological consequences of false-positive screening mammograms. Health Technol Assess. 2013;17(13):1-170, v-vi.

10. Chappy SL. Women's experience with breast biopsy. AORN J. 2004; 80(5):885-901.

11. Brett J, Austoker J. Women who are recalled for further investigation for breast screening: psychological consequences 3 years after recall and factors affecting re-attendance. J Public Health Med. 2001; 23(4):292-300.

12. Shaw CR, Wilson SA, O'Brien ME. Information needs prior to breast biopsy. Clin Nurs Res. 1994;3(2):119-131.

13. Lampic C, Thurfjell E, Bergh J, Sjödén PO. Short- and long-term anxiety and depression in women recalled after breast cancer screening. Eur J Cancer. 2001;37(4):463-469.

14. Gram IT, Lund E, Slenker SE. Quality of life following a false positive mammogram. Br J Cancer. 1990;62(6):1018-1022.

15. Barton MB, Moore S, Polk S, Shtatland E, Elmore JG, Fletcher SW. Increased patient concern after false-positive mammograms: clinician documentation and subsequent ambulatory visits. J Gen Intern Med. 2001;16(3):150-156.

16. Absetz P, Aro AR, Sutton SR. Experience with breast cancer, prescreening perceived susceptibility and the psychological impact of screening. Psychooncology. 2003;12(4):305-318.

17. Espasa R, Murta-Nascimento C, Bayés R, et al. The psychological impact of a false-positive screening mammogram in Barcelona. J Cancer Educ. 2012;27(4):780-785.

18. Monticiollo DL, Monsees B. Mammography and Patient Anxiety [e-letter]. Ann Fam Med. http://www.annfammed.org/content/11/2/106.figures-only/reply\#annalsfm_el_25667. Published Mar 28, 2013. Accessed Jun 14, 2013.

19. Brodersen J, Siersma VD. Long-term psychosocial consequences of false-positive screening mammography. Ann Fam Med. 2013;11(2): 106-115.

20. Brodersen J. Measuring Psychosocial Consequences of False-Positive Screening Results: Breast Cancer as an Example [dissertation]. Copenhagen, Denmark: University of Copenhagen; 2006.

21. Brodersen J, Thorsen H, Kreiner S. Validation of a condition-specific measure for women having an abnormal screening mammography. Value Health. 2007;10(4):294-304.

22. Brodersen J, Thorsen H. Consequences of Screening in Breast Cancer (COS-BC): development of a questionnaire. Scand J Prim Health Care. 2008;26(4):251-256.

23. Dufouil C, Brayne C, Clayton D. Analysis of longitudinal studies with death and drop-out: a case study. Stat Med. 2004;23(14):2215-2226.

24. Brodersen J, McKenna SP, Doward LC, Thorsen H. Measuring the psychosocial consequences of screening. Health Qual Life Outcomes. 2007;5:3.

25. DeFrank JT, Barclay C, Sheridan S, et al. The psychological harms of screening: the evidence we have versus the evidence we need. J Gen Intern Med. 2014;30(2):242-248. 